\title{
Study on social public security management in information era
}

\author{
YangJing \\ Hubei University of Police,Wuhan 430034,China
}

Keywords: Information age; social security management; hardware facilities; system function; management strategy

\begin{abstract}
In the information age, with the continuous development of science and technology, the computer plays an increasingly important role in the social security management and public security system. Information technology brings great convenience to the management of social security, but also encountered hitherto unknown challenge, this study analyzes the current situation of social security management in information era, from human resources, infrastructure, software and management methods, discusses the problems of the social security administration under the background of information, and then a detailed analysis of the social security management information system the function, and according to the function framework of information system, puts forward some measures of improving social security management in the information age, which has certain reference significance for the study of modern social security management method.
\end{abstract}

\section{Introduction}

With the continuous development of computer and network communication technology, especially cloud platform technology, the current society has begun to enter the era of information, provides great convenience for the development of computer management of social security and public security system, has an important significance for the social security management information system construction. Due to the lack of information talent, information infrastructure specialized backwardness and lack of modernized management system and method, information level of social security management is not high, and there are a lot of technical and management problems, only to overcome these problems, improve the social security management information system hardware and software level in the real sense, in order to improve the society the security management level in the information era.

\section{Social public security management status in the era of information}

With the advent of the information age, information technology has brought great convenience to the management of social security, but also encountered hitherto unknown challenge, which is mainly the informatization talent shortage, basic information and hardware construction and management mode, to solve these problems can make the information effectively promote the level and efficiency of social security management.

In the process of informationization of social security management, which need to grasp the comprehensive quality of talents of information technology and skilled public security business, because in the process of informationization, relying solely on the information infrastructure is unable to complete the information management goal, but in practice, few skilled public security service of the police also have higher information work the level in the information construction process must pay attention to this problem, pay attention to the cultivation of talents, in order to meet the demand of social security management talents in information age.

The construction of basic information and hardware facilities is backward, because there are some important leaders and police are not aware of the information technology brings to the management of social security, no attempt to bring the effect of information management, in the information construction process exists to meet up, there is no focus on informatization construction. 
Of course, the construction of hardware facilities and social security management information is not all, compared to the construction of hardware and software is also very important, if only pay attention to the construction of the hardware and infrastructure are not to use, or to update the information is not timely, not to be able to play an important function of information technology means.

A situation of backward management methods but also social security management information construction, public security management methods now are generally follows the traditional management method, has not been able to adapt to the information age management needs. Because some police's basic information collection and updating is not timely, the level of information collation and judgment is not high, and the rate of utilization and conversion of information is not high, which is the result of high cost of social security management and low income. In the process of social management informatization, it is necessary to combine information technology and signal management to improve the level of social security management.

\section{The function of information system and its function on Social Security Administration}

Public security information management system can effectively improve the efficiency of social security management information system, the main features include information collection and input, management of social security management information dissemination, information processing, information retrieval and information output, the overall function framework as shown in Figure 1.

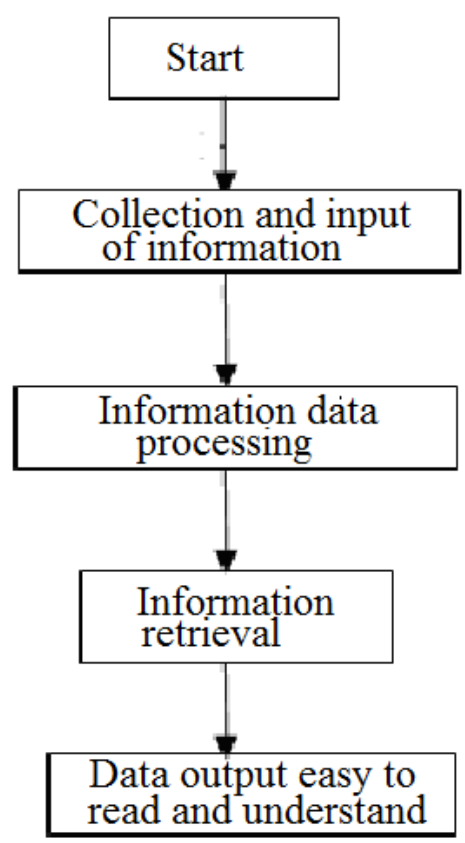

Fig. 1 The overall functional framework of information system

As shown in Figure 1 represents the overall function of social security management information system framework, the information system can be the original information data collection, using the method of data processing, data conversion for the public security system of special data, this is the most basic function of information system, is also the most primitive function. Another basic information system is the function of information transmission in the process of data collection and input, between the user and the system between the part of the need for data exchange and transmission of information, will spread to the local needs, can effectively improve the efficiency and level of public security information system, more conducive to improving the police.

Processing information is the core function of public security management information system, in the process of information system, the need for massive social security related information for data processing, statistical analysis of a large number of social security situation, and then obtain the comprehensive information, to provide convenience for the management of public security organs. 
The main function is to provide the public security information system construction of information storage and retrieval, the final output of public security information, after data collection and input, has become a public security system needs the information, data and information available to become police and useful, and provide real-time retrieval function. After querying to the needs of information, the system can output visual, understandable, intuitive and concise results through the visual interface, thus meeting the needs of the police. Public security information management system construction is conducive to achieve efficient operation of police work, computer information management has the characteristics of high speed, large capacity and high degree of automation, it can provide information quickly and accurately, and has the ability to store information and greatly fast classification, summary information, finally by providing information storage, retrieval and output function, save a lot of heavy daily manual labor, can improve the effective security management modernization level, improve work efficiency.

\section{The strategy of innovating social security management in the era of information}

In the information age, in order to improve the level of social security management, information combination networking platform of the information age, the social security administration of public security network service as the goal, in some economically developed regions. Things have become a social security management tool, and in a small range began to run, networking technology will become an innovative management way of social security management, security management information system based on Internet of things can be developed efficiently, so as to improve the efficiency and level of public security management.

Innovative management is a very important measure to improve social security management. Only by drawing on modern and innovative management model and innovating law enforcement management can we improve the credibility of law enforcement. In the process of informatization construction should explore management methods, constantly sum up experience, formed a set of standardized, scientific and efficient theory, combined with the development of information and now needs to use information management system, improve work efficiency, eventually forming a modern, high degree of information management.

Under the background of informationization, the innovation of social security management also requires a combination of virtual social management, with the emerge in an endless stream of network application, such as "QQ group", "Twitter class micro blog" and "WeChat" instant communication mode, with the birth of a large number of social networking groups and online community, in the innovation of social management, requires a combination of the product of the information age, according to the relevant laws and regulations to regulate the Internet these network group behavior, and combined with the modern era background, explore new management methods and normative documents, and the use of these popular means of communication, social security management services, and ultimately achieve a win-win effect.

\section{Conclusion}

The advent of the information age has brought great convenience to the design of social security management and public security information system, the information age under the background of social security management, security management information system functions are discussed, and combined with the status and function of information system proposed imformational era of social security management strategy. The degree of social information continues to accelerate, especially the emergence of cloud platform, has brought great changes to people's life, social security and management has also brought great pressure, only the combination of information technology, and continuously improve the social security management level, to meet the needs of social development, maintaining social stability. 


\section{Acknowledgement}

The work was supported by the research project of humanities and social science of Hubei provincial education department in 2016 with the project number $16 Y 144$ and the project name Research on social public security management in information era.

\section{Reference}

[1] Huang Shu'an. Practice and Reflection on promoting standardization and modernization of public security work by public security information technology [J]. public security research, 2009 (1).

[2] Yang Jun, Zhao Fuqiang. The main problems affecting the deepening of the reform of community policing at present and their causes and Countermeasures [J]. Journal of Shanghai Police Academy, 2006 (5).

[3] Huang Ming. Police modernization guided by public security information[J]. public security research, 2007 (2).

[4] Shi Liping, Zhang Yinghui, Luo Aling. The big data industry development opportunities and [J]. software guide,2015 (07).

[5] He Xiaoping, Huang Huanglong. Evolution path, research hotspots and frontier visual analysis of large data field [J]. modern information,2015 (04).

[6] Shi Ping. Big data era, innovation, government, social management[J]. Eastern corporate culture,2014 (19).

[7] Zhang Zhaoduan. Strategic thinking on the construction of public security big data[J]. Journal of Chinese People's Public Security University (SOCIAL SCIENCE EDITION),2014 (04).

[8] Zhao Qun Li. Social development mode of the security work in innovation[J]. Journal of Railway Police College, 2011 (4).

[9] Wang Dujuan. Study on urban social security problems[D].Zhengzhou University,2009.

[10]Zou long. Research on the exploration and development of police community policing mechanism in Shanghai [D].East China Normal University,2006.

[11] Hu Shu'e.security contract system of [D].Southwest University of Political Science and Law,2008.

[12] Liu Shiwen. The scientific system of modernization of public security administration in our country [J]. public security research,1999 (05).

[13]ZhaoWenyan. Analysis of the changes and Countermeasures of public security management[J].public security education,2002 (12).

[14] Zhang Yan. Analysis and research of database technology for mass data processing based on Internet of things[J]. Computer disk software and applications, 2014, 2 (19).

[15] Yao Lin. Policing strategy in the era of big data [J]. Journal of Beijing Police Academy,2014 (04).

[16] Shan Yong. Data management innovation, social security prevention and control system[J]. Socialism with Chinese characteristics. 2015 (04). 